\title{
Quantitative and Qualitative Research: Beyond the Debate
}

\author{
Omar Gelo • Diana Braakmann • Gerhard Benetka
}

\section{Erratum to: Integr Psych Behav (2008) 42(3):266-290}

\section{DOI 10.1007/s12124-008-9078-3}

In the original version of this article, Fig. 1 was misprinted with arrows at incorrect directions.

In the first line of figures:

(1) In the first line of figures (One-phase approach: Merge the data: Triangulation design), the arrow does not proceed from the middle (interpretation of QUAN + QUAL results) to the right (QUAL) box, but from the right to the middle box.

(2) In the second line of figures (One-phase approach: Embed the data: Embedded design), the arrow does not proceed from the last box on the right side to the second box from the right side, but from the second box from the right to the left one on the right side.

Correct Fig. 1 is given here.

The online version of the original article can be found at http://dx.doi.org/10.1007/s12124-008-9078-3.

O. Gelo $(\bowtie) \cdot$ D. Braakmann

Department of Psychotherapeutic Sciences, Sigmund Freud University_Vienna, Schnirchgasse 9a, 1030 Vienna, Austria

e-mail: omar.gelo@sfu.ac.at

G. Benetka

Department of Psychology, Sigmund Freud University-Vienna, Schnirchgasse 9a, 1030 Vienna, Austria 


\section{(I) One-phase approach}

(a) Merge the data:

Triangulation design

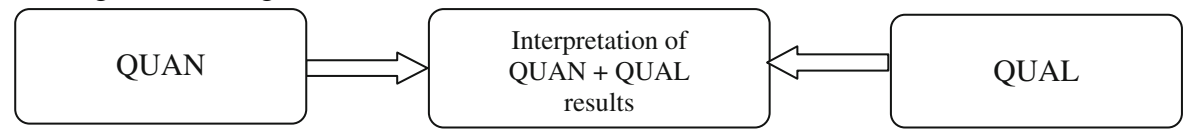

(b) Embed the data:

Embedded design

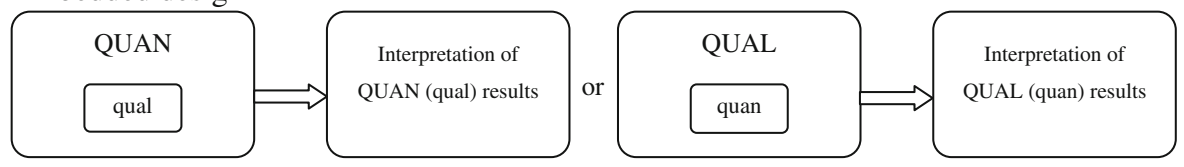

\section{(II) Two-phase approach}

(a) Connect the data:

Explanatory design

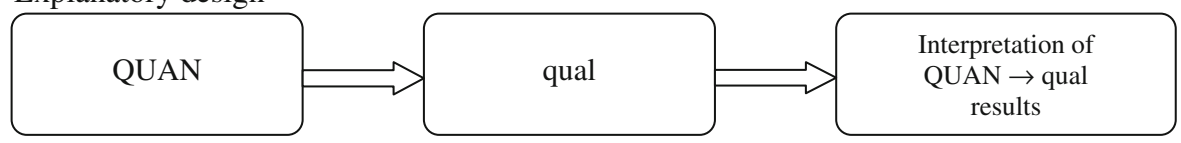

Exploratory design

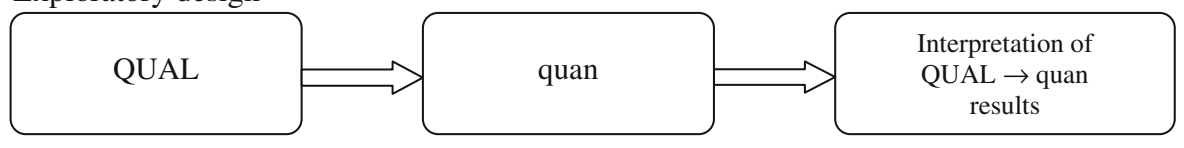

\section{(b) Embed the data:}

Embedded design

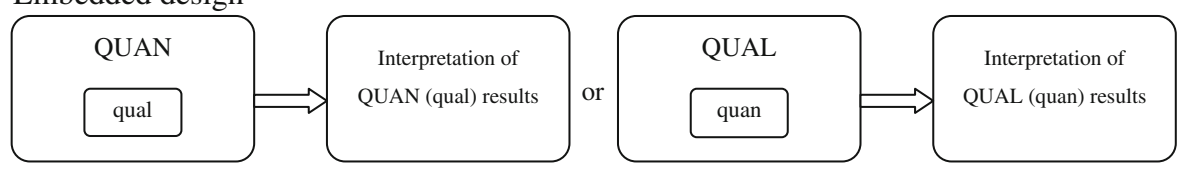

Fig. 1 Mixed methods research designs (modified from Creswell \& Plano Clark 2007) 